\title{
PRÁTICAS DOCENTES NA EDUCAÇÃO SUPERIOR TECNOLÓGICA: A FORMAÇÃO DE COMPETÊNCIAS DEMANDADAS DOS PROFISSIONAIS NA ECONOMIA DIGITAL
}

\section{TEACHING PRATICES IN TECHNOLOGICAL HIGHER EDUCATION: THE FORMATION OF DEMANDED SKILLS OF PROFESSIONALS IN THE DIGITAL ECONOMY}

\author{
Sergio Pamboukian ${ }^{1}$, Roberto Kanaane ${ }^{2}$
}

\section{RESUMO}

O artigo visa discutir as práticas docentes adotadas em cursos superiores tecnológicos, objetivando responder às mudanças impostas pelos processos de transição da sociedade contemporânea, para uma economia digital. Foi realizada uma pesquisa quanti-quali utilizando o método explicativo conjugado com a abordagem de estudo de caso. Foram adotadas as técnicas de pesquisa bibliográfica junto à literatura científica, contemplando o estado da arte da temática da investigação, assim como a pesquisa de campo por meio de aplicação de questionário eletrônico para coleta de dados por meio dos docentes. O objeto de estudo constituiu-se nos Cursos Superiores Tecnológicos oferecidos por uma Instituição Estadual de Ensino Superior Tecnológico em São Paulo, à qual estão vinculados os pesquisadores. Os resultados apontam a necessidade de diversificar acervo de práticas docentes e de realinhar a formação docente, visando atender às demandas de uma geração de nascidos digitais que atuará em uma economia digital.

PALAVRAS-CHAVE: Economia Digital. Práticas Docentes. Competências. Cursos Superiores Tecnológicos.

\section{ABSTRACT}

The article aims to discuss the teaching practices adopted in technological higher education courses aiming to respond to the changes imposed by the transition processes of contemporary society to a digital economy. A quanti-quali research was performed using the explanatory method combined with the case study approach. The bibliographic research techniques were adopted along with the scientific literature contemplating the state of the art of the research theme, as well as the field research through the application of an electronic questionnaire for data collection through the teachers. The object of study was the Technological Higher Courses offered by a State Technological Higher Education Institution in São Paulo, to which the researchers are linked. The results point to the need to diversify the collection of teaching practices and to realign teacher training in order to meet the demands of a digital born generation that will act in a digital economy.

KEYWORDS: Digital Economy. Teaching Practices. Competences. Technological Colleges.

1 Aluno Especial de Doutorado IPEN (atual), Mestre em Educação Profissional pelo Centro Paula Souza (2018), Especialização MBA em Gestão Empresarial pela Fundação Getúlio Vargas (2004), Graduação em Licenciatura Plena em Mecânica pela Universidade Estadual Paulista Júlio de Mesquita Filho (1989), Graduação em Tecnologia Mecânica Modalidade Soldagem pela Faculdade de Tecnologia de São Paulo (1986). Executivo, no Brasil e exterior, foi Professor Tutor dos Cursos de MBA do FGV Online e Professor do Curso de Tecnologia em Mecânica Processos de Soldagem na FATEC Itaquera. Tem experiência em Engenharia com ênfase em Soldagem, Consultoria de Gestão e Educação. Atua no corpo Docente da Faculdade de Tecnologia de São Paulo e SENAI Nadir Figueiredo (Osasco). ORCID ID http://orcid. org/0000-0002-2542-1464. Correio eletrônico: sergio.pamboukian@fatec.sp.gov.br

2 Psicólogo, Pedagogo, Professor Doutor em Ciências pela Universidade de São Paulo - USP - Instituto de Psicologia; Membro da Academia Paulista de Psicologia - cadeira 21; Professor e Orientador do Programa de Mestrado em Gestão e Desenvolvimento da Educação Profissional, mantido pelo CEETEPS - Centro Estadual de Educação Tecnológica paula Souza. Autor de livros na área de Gestão de Pessoas, Desenvolvimento do Potencial Humano, Ética em Turismo e Hotelaria, junto a Editora Gen Atlas. ORCID ID https://orcid.org/0000-00024702-7740, correio eletrônico: kanaanhe@gmail.com 


\section{1- Introdução}

O artigo surge no contexto de continuidade de pesquisas concernentes ao tema tratado em dissertação de Mestrado em Gestão e Desenvolvimento da Educação Profissional e Tecnológica que buscou identificar quais as competências requeridas dos profissionais do século XXI face aos efeitos da quarta revolução industrial em andamento (PAMBOUKIAN, 2018). A reflexão prosseguiu na direção de investigar as práticas docentes no novo milênio de Instituição de Ensino Superior (IES) objetivando responder às mudanças impostas pelos processos de transição da sociedade para uma economia digital.

O estudo está estruturado em seis seções: a primeira introduz a problemática a ser discutida e a metodologia; a segunda apresenta breve fundamentação teórica com respeito às mudanças no trabalho e educação na era da Economia Digital; a terceira descreve as competências requeridas dos profissionais na Economia Digital; a quarta destaca o debate sobre as práticas docentes para o século XXI; a quinta sinaliza os resultados e discussões decorrentes da pesquisa junto à população alvo. Na última seção tem-se as considerações finais, proposições e oportunidades de novos estudos referentes ao tema.

Richter et al (2018) descrevem a acelerada expansão das tecnologias digitais de conectividade nos países industrializados como um fenômeno disruptivo que tem ocasionado a desarticulação de indústrias, alterado os padrões de competitividade e o comportamento nos mercados, aprofundado as mudanças econômicas e sociais. Como consequência de tal fenômeno, constata-se que o declínio na atividade industrial vigente nos países emergentes ocorre também nos países desenvolvidos. Nessas condições, crescem os questionamentos sobre os processos de desindustrialização, as dificuldades do desenvolvimento das economias, a restrita importância da indústria de transformação e o crescimento dos obstáculos à geração de empregos de qualidade.

Zaslavskaya (2018) compreende que é justamente nesse contexto que os processos de globalização podem ter impacto significativo na melhoria do sistema educacional contemporâneo, especialmente na introdução de atividades que preparem os estudantes para uma economia digital. A rápida obsolescência do conhecimento eleva a relevância da educação e justifica a necessidade de uma nova abordagem educacional baseada em metodologias de aprendizagem emergentes.

Para Silva e Bezerra (2018), as IES por todo o mundo estão submetidas à uma pressão sem precedentes devido à modificação do estilo de vida da sociedade em transição rumo a uma economia digital. Os autores vislumbram um novo mercado de trabalho que requer profissionais com elevado nível de conhecimento, habilidades e atitudes e que desempenhem competências antes não exigidas. Dentre os desafios enfrentados para a incorporação das tecnologias digitais na cultura acadêmica destacam a implementação de práticas docentes que favoreçam a utilização de forma crítica e criativa dessas tecnologias para a aprendizagem de maneira a transformar as realidades educacional e social.

Richter et al (2018) identificam a existência de um descompasso entre o conjunto de habilidades profissionais de nível superior requeridas pelos empregadores quando comparadas às promovidas pelas políticas públicas, o que fornece indícios de que os sistemas de ensino superior não estão preparados para satisfazer às exigências do mercado de trabalho. Os autores relatam os esforços nos países desenvolvidos como Alemanha, EUA, Japão, Coréia do Sul, entre outros, para a integração das universidades, governos e empresas visando uma ampla mudança institucional, através de políticas de evolução do ensino superior na busca de conhecimento de ponta, a partir de trajetórias e percursos formativos baseados na inovação tecnológica. Em tais países, os formuladores de políticas educacionais têm privilegiado o desenvolvimento de habilidades necessárias para ocupar profissões não rotineiras, com elevado valor agregado e integradas aos elos da cadeia global de fornecimento. Nestes países, o ensino superior foi identificado como uma área de política crucial para o atingimento dos objetivos dos governos e de empregadores, através do alinhamento entre o ensino superior e as necessidades do mercado de trabalho, dos setores, baseados no conhecimento.

Para Arbix et al (2017), no Brasil, o debate sobre a indústria do futuro, além de se voltar para a elevação da sua produtividade, procura identificar oportunidades para a transformação estrutural da economia, atingida conjunturalmente por uma grave crise econômica, mas duplamente exposta pelos avanços que emergentes em outros países, seja pela baixa capacidade de inovação tecnológica, seja por sua dependência da exportação de 
commodities. Para os autores, o país necessita urgentemente de um programa robusto orientado para apoiar a reestruturação e capacitação da indústria brasileira.

Nesse sentido, para Dantas, Pamboukian e Kanaane (2017), o Brasil possui latente potencial de desenvolvimento econômico em diversos setores, tais como o de óleo \& gás, infraestrutura e energias renováveis. Os autores identificam que a retomada da produção industrial no país trará a substituição dos processos obsoletos operados através de equipamentos analógicos por outros processos mais inteligentes e digitais, a fim de atenderem as exigências de controle, rastreamento e monitoramento dos processos, resultando assim, na elevação da produtividade.

Consequentemente, Pamboukian e Kanaane (2017) apontam o desafio de suprir o descompasso entre a quantidade de pessoas qualificadas e de profissionais capacitados para superar o desafio de inserir as indústrias e IES no contexto da produção automatizada, visando elevar a competitividade das empresas brasileiras frente ao mercado mundial. No entanto, os autores concebem a necessidade de adequação dos cursos superiores à nova realidade de transformação do mercado industrial, por meio da aproximação das IES às empresas, de forma a reduzir o hiato existente entre a academia e o mercado de trabalho.

Segundo Fini (2018), são justamente as profundas alterações ocorridas no mundo contemporâneo que devem permear a discussão a respeito dos processos de ensino-aprendizagem necessários à formação para o trabalho. A autora reforça que a elevada velocidade das transformações na sociedade para a produção de conhecimento tornou provisórias as verdades construídas no saber-fazer científico, e, por conseguinte, o processo de formar profissionais necessita adequação à essa agilidade da produção e disseminação do conhecimento científico. Conclui que se faz necessária uma mudança paradigmática na educação, seja na concepção de quem e de como aprende, de quem e como ensina; seja na arquitetura dos currículos e nas relações das IES com o mundo do trabalho.

Lacerda e Santos (2018) relatam que o mercado de trabalho requer dos egressos dos cursos superiores, além das competências técnicas, competências sócioemocionais tais como trabalho em equipe e resiliência, além de competências cognitivas como senso crítico, senso interdisciplinar e resolução de problemas complexos.
Em função do exposto, questiona-se: quais as práticas docentes que contribuem para o desenvolvimento das competências profissionais necessárias à economia digital?

O objetivo geral centrou-se em identificar as práticas docentes que contribuem para o desenvolvimento das competências profissionais necessárias à economia digital.

O objetivo específico constituiu-se em verificar as metodologias de ensino-aprendizagem aplicáveis ao nível superior apropriadas ao atendimento das demandas do século $X X I$.

Realizou-se uma pesquisa quanti-quali (SAMPIERI; COLLADO; LUCIO, 2013) utilizando o método explicativo conjugado com a abordagem de estudo de caso. Foram adotadas as técnicas de pesquisa bibliográfica junto à literatura científica contemplando o estado da arte da temática investigada, assim como a pesquisa de campo por meio de aplicação de questionário eletrônico para coleta de dados com escala não Lickert entre 1 (Discordo Plenamente) e 10 (Concordo Plenamente), além de espaço para comentários.

Os dados quantitativos foram tabulados pelo software Google Docs e foi realizada análise estatística das respostas. Dos comentários e da questão aberta foram obtidos dados qualitativos submetidos à análise interpretativa textual.

O objeto de estudo constituiu-se dos CST oferecidos por uma instituição de ensino tecnológico superior à qual estão vinculados os pesquisadores. Os sujeitos de pesquisa foram os Professores de todos os cursos oferecidos pela instituição de ensino superior, num universo de 295 professores. Foi utilizada uma amostra não probabilística, contemplando todas as respostas obtidas no período em que o questionário esteve disponível, ou seja, entre 20/05/2019 e 15/06/2019, constituindo-se numa amostra de 44 professores, correspondendo a $14,9 \%$ do universo de professores.

\section{2- Negócios, Trabalho e Educação na era da Econo- mia Digital.}

Tapscott (1995) caracterizou a economia digital como uma economia em que as organizações utilizam a tecnologia da informação para transformar os processos de negócios e as formas como os produtos e serviços são criados e comercializados. Esta nova economia é 
catalisada pela hiperconectividade, que criou um ambiente econômico surgido da digitalização de conexões em tempo real, interação entre pessoas, dispositivos e empresas de forma colaborativa, de maneira que as empresas, os processos, os dados e as coisas, enfim, tudo possa ser conectado em uma rede. Dentre as empresas pioneiras que criaram novos modelos de negócios incluem-se o Airbnb, o Waze e o Uber.

A transformação digital da economia revela as competências profissionais a serem consideradas relevantes nos programas educacionais. Os conhecimentos e habilidades necessários em um novo e complexo mundo implicam mudanças na esfera do emprego e da educação profissional. Há indicação do crescimento do emprego na economia criativa, economia digital, economia virtual, economia da preservação ambiental e serviços orientados ao homem. Especialistas esperam o crescimento do emprego nesses setores da economia com consequente aumento na demanda por profissionais. As qualidades e competências profissionais serão focadas no desenvolvimento da criatividade humana, enquanto atividades de rotina físicos e intelectuais tendem a cair em desuso (BARSUKOV et al, 2018).

Arbixet al (2017) descreveram que a estratégia dos países desenvolvidos de transferir a produção de bens de baixo valor agregado para os países em desenvolvimento resultou a transferência da produção de produtos de maior complexidade, ocasionando a perda de capacidade industrial de produção de bens de maior complexidade. Os autores relatam que tal fenômeno se tornou flagrante a partir da mudança da produção de smartphones, computadores, telas de alta resolução, materiais avançados, semicondutores, diodos e sensores para os países asiáticos. A perda de capacidade industrial das economias maduras estaria vinculada não somente à transferência de empresas para países emergentes, mas também à integração da cadeia de fornecimento por meio de processos avançados de produção à economia digital.

Bonvillian e Sanjay (2018) registraram a eliminação de um terço dos empregos industriais nos EUA no período entre 2000 e 2010, cerca de 5,8 milhões de postos de trabalho. Como consequência, ocorreu a substituição de parte significativa dos trabalhadores com média escolaridade por outros com diploma de ensino superior, cristalizando um consenso crescente de que a adoção de tecnologias digitais e a criação de empregos de maior grau de complexidade implicam na necessidade de elevação do nível de educação dos trabalhadores.

Como resultado, Pamboukian e Kanaane (2018b) alertam que a era da transformação digital trouxe incertezas acerca do futuro do trabalho e das profissões. Os autores ressaltam que o desafio na educação é romper com um ensino tradicional superado, por meio de uma adequação das práticas de ensino às novas demandas da sociedade, através do uso das metodologias ativas de ensino-aprendizagem combinadas com as tecnologias digitais. O que está em questão são os papéis do professor e do aluno, de forma que este se torne o protagonista do processo e não mais um coadjuvante passivo. Tal fato converge com a posição de Fava (2018), de que as transformações das profissões atuais nos próximos anos e na própria educação devido à integração das tecnologias digitais, da robotização, da automação e da inteligência artificial no mundo do trabalho requer a reinvenção da educação e de um novo papel dos alunos e professores na preparação dos atuais estudantes para seu futuro profissional, posto que as habilidades necessárias para os profissionais do futuro estarão atreladas aos impactos trazidos por tais tecnologias.

Conforme Zalavskaya, (2018), a educação como um dos setores mais importantes da atividade humana é influenciada pelas metodologias ativas de aprendizagem provocando mudanças nos sistemas tradicionais de educação. O uso das tecnologias de informação e comunicação (tic) melhora a competitividade da economia, amplia as possibilidades de sua integração ao sistema mundial, contribui para a informação global, o intercâmbio, a formação e seleção de futuros profissionais, por meio de uma liderança responsável e capaz de trabalhar com criatividade, inovação e empreendedorismo, inteligência social, pensamento adaptativo, intercolaboração cultural, características essenciais para o trabalho futuro.

Para Schwab (2016), a mudança de paradigmas na economia, nos negócios, na sociedade e dos próprios indivíduos vem impactando de tal forma que a mudança já não envolve mais só "o quê" e "o como" fazer as coisas, mas inclui "quem são" os indivíduos. Para o autor, uma rede mundial de pessoas interconectadas por meio de dispositivos móveis de elevada capacidade de processamento e armazenamento, interagindo sobre a confluência de tecnologias como a inteligência artificial (Al), a internet das coisas (IdC), veículos autônomos, nanotecnologia, biotecnologia e computadores quânti- 
cos, entre outras, delineia mesmo que ainda de forma indefinida, os contornos desta revolução da sociedade.

Nesse sentido, o documento da Confederação Nacional da Indústria (CNI, 2016) descreve que a incorporação das tecnologias digitais à atividade industrial criou a chamada Indústria 4.0 ou $4^{a}$ revolução industrial, por meio do surgimento de uma economia digital decorrente da integração e o controle da produção a partir de sensores e equipamentos conectados em rede que permitem a fusão do mundo real com o virtual. Nas novas "indústrias inteligentes", máquinas e insumos "conversam" ao longo das operações industriais, da forma que a escala e a flexibilidade do processo fabril ocorrem de forma autônoma e integrada através de dispositivos localizados nas empresas, que efetuam o intercâmbio de informações de forma instantânea a respeito de compras e estoques, otimizando a logística e promovendo maior integração entre os elos da cadeia produtiva.

Com a finalidade de se compreender a interface entre Negócios, Trabalho e Educação na economia digital faz-se necessária a caracterização das competências requeridas dos profissionais diante das mudanças sinalizadas.

\section{3 - Competências Profissionais.}

Segundo Tobón (2013), a educação por competências é uma estratégia que objetiva a formação integral das pessoas por meio de um processo de planejamento, implementação, avaliação e gestão do projeto educacional visando promover o domínio de uma série de competências que resultem em um desempenho que evidencie o saber, o saber fazer e o saber ser em diferentes contextos e incentive a capacidade de resolver problemas complexos, contribuindo com o desenvolvimento social, econômico, cultural e ambiental num constante desafio de flexibilidade e melhoria contínua.

Pereira e Silva et al (2017) concebem que a complexidade do conceito de competência ao envolver mais do que conhecimentos e habilidades, tornou-se central como objetivo educativo na formação dos indivíduos para agirem em contextos de vida e trabalho globais, complexos e exigentes. Todavia, para os autores, perseguir tal objetivo implica uma mudança de paradigma nos sistemas educacionais, deslocando o foco do ensino a partir do professor e no conhecimento transmissível ao aluno para a aprendizagem não só dos conhecimentos, mas também, das habilidades e das atitudes, ou seja, das competências. Esta mudança está vinculada a ação direta dos professores, numa dupla articulação das competências: do ensino por parte dos docentes e da aprendizagem por parte dos discentes, de modo a mobilizar em ambos as competências que possibilitam a aprendizagem. A dificuldade existente é como converter currículos pensados numa matriz de transmissão de conhecimentos em currículos baseados no desenvolvimento de competências, bem como estabelecer quais devem ser as competências profissionais dos professores, em particular no domínio das práticas docentes.

Em resposta à tal dificuldade, Fadel, Bialik e Trilling (2015) apresentaram o modelo para estruturação de currículo educacional elaborado pelo CCR (Curriculum Corsortium Research), iniciativa da OCDE (Organização de Cooperação e de Desenvolvimento Econômico) que visa até 2030 padronizar a educação nos países membros. O modelo sumariza e compara os principais referenciais de internacionais de competências, reduzindo-os a apenas quatro dimensões. Desta forma, o CCR sintetiza na dimensão do conhecimento todo o conteúdo acadêmico e de letramento; na dimensão das habilidades, inclui a cooperação, o pensamento crítico, a criatividade, a tomada de decisão, a solução de problemas e a inovação; na dimensão do caráter, enquadra as habilidades comportamentais, sociais e emocionais e por fim, na dimensão do meta-aprendizado, considera a reflexão e a capacidade de aprender a aprender (FADEL; BIALIK; TRILLING, 2015), conforme representado no quadro 1 a seguir:

Quadro 1 - Competências dos profissionais da economia digital

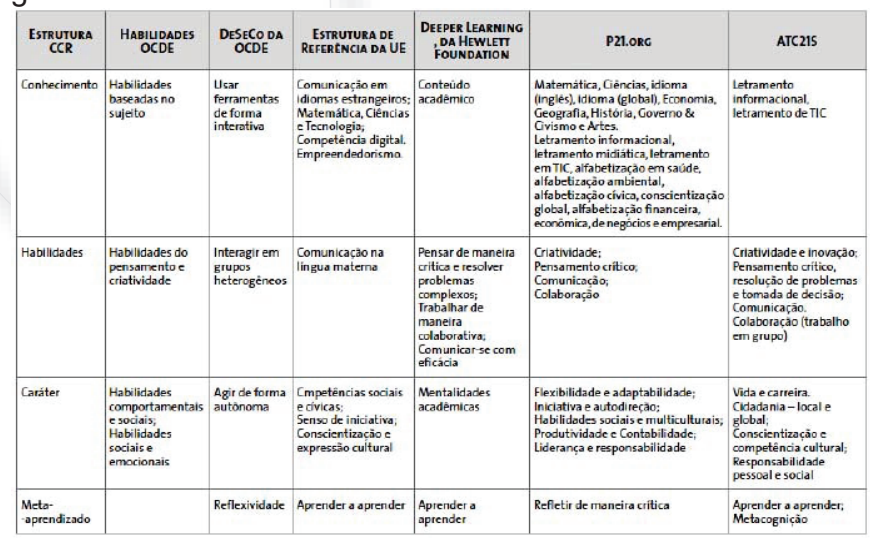

Fonte: Fadel, Bialik e Trilling, (2015) 
Pamboukian (2018) adotou a estrutura de referência da União Europeia (UE) em estudo acerca das competências requeridas dos profissionais egressos dos Cursos Superiores de Tecnologia. Pamboukian e Kanaane (2018a) relatam as sugestões dos professores a respeito das práticas docentes necessárias visando o desenvolvimento das competências dos alunos dos CST em Mecânica Modalidade Processos de Produção, Mecânica Modalidade Projetos, Soldagem e Mecânica de Precisão da Fatec-SP, conforme tabela 1 a seguir:

Tabela 1 - Práticas docentes sugeridas pelos Professores da Fatec-SP

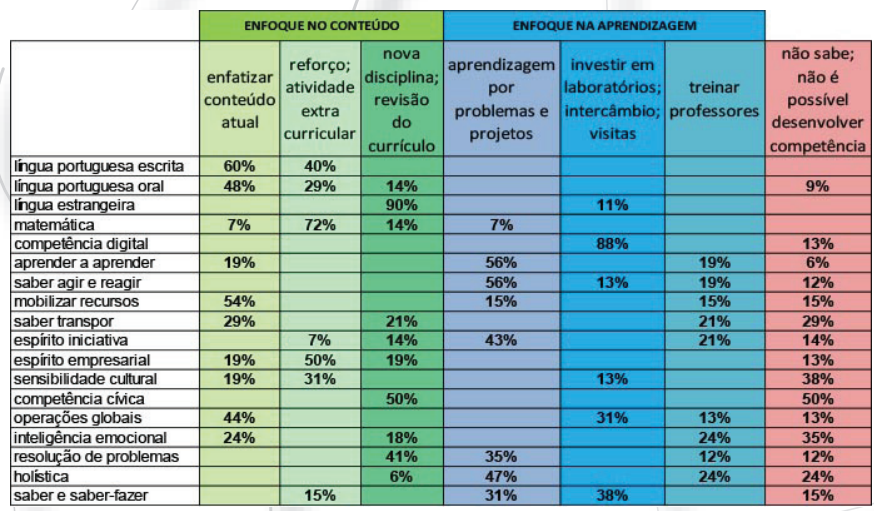

Fonte: Adaptado de Pamboukian e Kanaane (2018a)

As dezoito competências pesquisadas foram classificadas como extremamente relevantes ou muito importantes pelos empregadores (PAMBOUKIAN, 2018). As sugestões dos professores dos CST da Fatec-SP a respeito das práticas docentes que propiciam o desenvolvimento das competências requeridas dos profissionais no século XXI apresentadas na tabela 1 demonstram a necessidade de atualização do currículo para desenvolvimento da competência de comunicação em língua estrangeira reportada por $90 \%$ dos docentes pesquisados, bem como a necessidade de investimento em TIC para desenvolvimento da competência digital sugeridos por $88 \%$ dos pesquisados.

Fica evidenciada a necessidade de alterações no conteúdo e também na metodologia de ensino-aprendizagem para o nível superior, a fim de se possibilitar o desenvolvimento das competências, independentemente do referencial de competência adotado. Nesse sentido, infere-se que as competências profissionais necessárias para a economia digital estão vinculadas, por um lado, ao processo educacional, por meio de práticas docentes que se constituem em um mecanismo indutor deste processo, e por outro, às políticas públicas e diretrizes educacionais.

\section{Práticas Docentes na Educação Superior Tecno- lógica.}

Entende-se que a utilização conjunta de determinadas práticas docentes possibilitam o desenvolvimento das competências necessárias na economia digital. Entretanto, persiste na educação tradicional a visão de que o docente é o único responsável pela aprendizagem, enquanto detentor do saber e das técnicas de ensino. Tal visão reduz o discente a um expectador passivo, que recebe os conteúdos por meio de disciplinas compartimentadas, de uma forma padronizada, que busca ensinar e avaliar a todos com a mesma métrica, num arranjo de sala de aula em forma de plateia resultando num modelo com limitada eficácia. No entanto, há iniciativas de se buscar formas de ensino que utilizem novos processos de organização do currículo e de novas metodologias de aprendizagem com tempos e espaços remodelados, alinhadas às demandas da sociedade contemporânea $e$ do mercado de trabalho, as quais requerem dos egressos competências cognitivas, pessoais e sociais como proatividade, colaboração e visão empreendedora que não são adquiridas pela forma convencional de ensino (CASTRO et al, 2015); (MORÁN, 2015).

As instituições de ensino superior em conjunto com seu corpo docente exercem o papel na formação do perfil profissional demandado pelo mercado, sendo necessárias adequações no processo de ensino que auxiliem o educando a construir tais competências através da reestruturação dos modelos de ensino no nível superior, uma vez que as abordagens didáticas tradicionais deixam de atender às especificidades requeridas pela sociedade contemporânea. Os métodos e modelos não tradicionais de ensino podem contribuir nessa transformação, auxiliando na construção de uma formação de nível superior integral, agregando competências e preparando profissionais mais capacitados para o mercado de trabalho, de forma que os alunos assumam o desenvolvimento de aprendizagens fundamentais para o profissional do século $X X I$, em acordo com sua futura profissão e atendendo às exigências e tendências. $O$ estímulo à pesquisa induz os alunos a desenvolverem o 
senso crítico e de solução de problemas reais da sociedade por meio de utilização das tecnologias (LACERDA; SANTOS, 2018).

Assim sendo, os processos educativos anacrônicos do século XIX, encerrados em quatro paredes, limitados temporalmente no horário de aulas e baseados numa relação em que alguém que detém o conhecimento o transmite aos demais necessitam ser revisados. As instituições de ensino se deparam com o desafio de construir um projeto pedagógico que contemple as inovações tecnológicas, a interatividade, a participação efetiva dos estudantes no processo de aprendizagem a partir de uma pedagogia para o século XXI (MASETTO; NONATO; MEDEIROS, 2017).

Portanto, a organização escolar requer transformação a fim de que todos aprendam, integrando os aspectos individual e social, os diversos ritmos, métodos e tecnologias, visando formar cidadãos plenos em todas as dimensões. As redes digitais possibilitam organizar o ensino e a aprendizagem de forma mais ativa, dinâmica e variada, privilegiando a pesquisa, a interação e a personalização dos estudos, em múltiplos espaços e tempos presenciais e virtuais. Diante deste quadro, entende-se que a educação não passará incólume pelas transformações sócio-político-econômicas observadas nas últimas décadas sem sua própria "reinvenção" (ARAÚJO, 2011).

Segundo Pereira e Silva et al (2017) o desenvolvimento das competências dos discentes requer professores dispostos à uma mudança de postura, que reconheçam a relevância das competências para si próprios como profissionais, assim como relevantes do ponto de vista educativo na formação dos alunos, na capacitação dos professores, transformando-se no fio condutor da compreensão do conjunto de competências elencadas na literatura internacional enquanto competências para a vida.

Segundo Fini (2018) as metodologias ativas surgem como proposta para transformar o processo de ensinar e de aprender na busca da participação ativa de todos. Em contrapartida ao enfoque tradicional estabelecido e consolidado, tem-se adotado metodologias ativas de ensino e aprendizagem que estimulam o reconhecimento dos problemas do mundo atual, que capacitam alunos a intervir e transformar a realidade. $O$ aluno se torna protagonista na construção de seu conhecimento, sendo responsável pela sua trajetória e pelo alcance de seus objetivos, ou seja, a metodologia ativa de aprendizagem refere-se a um processo amplo cuja principal característica é a inserção do discente como responsável pela sua aprendizagem e comprometido com seu aprendizado.

Os métodos contemporâneos de ensino podem ser a resposta ao contexto sinalizado, auxiliando na construção de uma formação de nível superior integral, agregando competências e preparando profissionais capacitados e sintonizados com o mercado de trabalho. As IES possuem importante papel na formação desse perfil profissional esperado pelo mercado, sendo necessárias, para tanto, adequações no processo de ensino e aprendizagem de forma a auxiliar o educando a construir tais competências. Nesse contexto, e diante da atual conjuntura socioeconômica, torna-se necessária a ressignificação do modelo de ensino no nível superior, uma vez que as abordagens didáticas tradicionais amiúde deixam de atender às especificidades requeridas pela sociedade contemporânea (LACERDA; SANTOS, 2018). Corroborando tal visão, tem-se a posição de Zaslavskaya (2018), a qual sinaliza que:

na era da quarta revolução industrial, os métodos de ensino estão sujeitos a transformações radicais: a hierarquia vertical é substituída por uma rede de interação; a competição e rivalidade entre profissionais é substituída por cooperação. Nesse contexto, o docente lida constantemente com a solução de problemas, posto que já não mais apenas ensina, mas cria as condições para a motivação, determinação e desenvolvimento de seus alunos. O professor no contexto de uma economia digital necessita de qualidades que irão ajudá-lo a responder a qualquer situação não-prevista, de forma que apenas um professor que possui a predisposição para lidar com aspectos fora de seu controle e por vezes de seu conhecimento, pode administrar. Assim, o professor no contexto contemporâneo se depara com a tarefa de não apenas educar, mas desenvolver pessoas éticas, empreendedoras, competentes, autônomas, capazes de tomar decisões profissionais, prever as consequências de seus atos e propor soluções em cooperação com outros profissionais (ZASLAVSKAYA,2018, traduzido pelos pesquisadores). 
Evidencia-se que a visão de Zaslavskaya adiciona aos conhecimentos as competências sócioemocionais, que por meio da interação e cooperação entre as pessoas, desenvolvam-se o empreendedorismo, a autonomia e aética.

Rodrigues e Teles (2019) apontam que os modos de compartilhar conhecimentos nos dias atuais demandam, em diferentes áreas do saber, profissionais que acompanhem o ritmo das transformações da sociedade. Professores, especialmente por lidarem coma formação intelectual dos alunos, estão no epicentro das buscas e adaptações dos meios de ensino e aprendizagem, que variam de acordo com os avanços da tecnologia.

As mudanças trazidas pelas TIC nas organizações promovem reflexões sobre a forma que são desenvolvidas as tarefas do professor. Estudos globais acerca das tendências de transformação dos sistemas educacionais tendo em vista uma economia digital sinalizam que o conhecimento enciclopédico tende a ser pouco demandado e que se requer uma mudança na metodologia de aprendizagem (ZASLAVSKAYA, 2018).Estas práticas docentes estão no quadro 2 a seguir:

Quadro 2 - Práticas Docentes para o século XXI

\begin{tabular}{|l|l|}
\hline \multicolumn{2}{|c|}{ PRÁTICAS DOCENTES } \\
\hline $\begin{array}{l}\text { Limitação de aulas expositivas e } \\
\text { Aprendizagem por Problemas e Projetos }\end{array}$ & Utilização de Inovações em Softwares \\
\hline E-learning & Redes Sociais \\
\hline Aprendizagem Hibrida & Atualizacão constante de conteúdos \\
\hline Aprendizagem Invertida & Educação personalizada \\
\hline Adição de jogos & Educação coletiva \\
\hline Aprendizagem móvel, remota e flexível & Aprendizagem integrada. \\
\hline Armazenamento em nuvem & $\begin{array}{l}\text { Uso de hardwares e softwares de gestão da } \\
\text { sala de aula }\end{array}$ \\
\hline Informações de Midia & $\begin{array}{l}\text { Perfil de um novo padrão profissional de } \\
\text { professores para século XXI }\end{array}$ \\
\hline
\end{tabular}

Fonte: Adaptado de Zalavskaya, (2018)

Zaslavskaya (2018) reforça a introdução das metodologias ativas em substituição às aulas expositivas como uma estratégia irreversível e que requer treinamento dos docentes para o domínio das TIC, bem como das metodologias de aprendizagem. A autora descreve que estudos acerca das tendências globais do desenvolvimento de sistemas educacionais apontam o uso das TIC para otimizar a competitividade da economia, ampliar as possibilidades de sua integração ao sistema mundial, elevar a eficiência e o autogoverno. Nestas condições, as TIC proporcionam oportunidade para o intercâmbio global de informações, formação e seleção de futuros trabalhadores, levando em conta as incertezas, tornando-os capazes de trabalhar em situações de criatividade, inovação e empreendedorismo.

Para Rodrigues e Teles (2019), na contemporaneidade, professores que se adaptam e se preocupam em acompanhar o tempo e as demandas dos alunos se mostram preparados para agregar valor às suas práticas de ensino; dito de outra forma, quanto menos alheios às transformações sociais da contemporaneidade, mais esses profissionais têm facilidade de promover processos de ensino e aprendizagem que sejam, de fato, efetivos, dinâmicos e colaborativos.

Segundo Schwartz et al (2019), os professores que adotam metodologias de aprendizagem centradas no aluno tiveram suas práticas docentes significativamente impactadas através do conhecimento e pela utilização de conceitos da neurociência da aprendizagem.

As tecnologias de informação e comunicação (TIC) devem ser encaradas não mais como ferramentas pedagógicas na educação, mas como base para uma nova metodologia de ensino-aprendizagem que permite a personalização do ritmo e a maneira que cada aluno aprende. Sua combinação com as metodologias ativas de ensino como aprendizagem por problemas e projetos através da solução de problemas reais surgem como aliadas da educação no século XXI, permitindo mitigar os conflitos intergeracionais, possibilitando aos docentes se adaptar à nova realidade dos alunos, suplantando a educação em massa, proporcionando uma aprendizagem individualizada demandada pelas novas gerações.

Zaslavskaya (2018) acrescenta competências docentes requeridas pela economia digital no tocante à escolha de metodologias de aprendizagem, foco em questões de direitos, acordos de licenciamento e uso da propriedade intelectual. Assim, o escopo de trabaIho docente foi ampliado da tarefa de apenas educar e formar pessoas com princípios morais e competências. Ele deve ser capaz de desenvolver profissionais independentes, empreendedores, aptos a tomar decisões e prever as consequências das suas decisões, em cooperação com uma visão global. O sistema educacional que prepare para uma economia digital deve propiciar mobilidade, dinamismo, desenvolver a habilidade de aprender a aprender e contribuir para a formação de uma responsabilidade global.

Para Fini (2018), a cultura das IES no Brasil requer transformação visando promover uma aprendizagem cooperativa, o desenvolvimento de habilidades cognitivas e 
sócioemocionais, proposição de processos que desenvolvam a habilidade de aprender a aprender e o incentivo à criatividade. Refletir sobre como adotar e implantar "metodologias inovadoras de aprendizagem e suas relações com o mundo do trabalho como um desafio para a transformação de uma cultura" torna-se imperioso.

Para Rodrigues e Teles (2019), o uso de tecnologia como estratégia pedagógica com os alunos requer planejamento. Para o sucesso das atividades por meio das TIC, o professor necessita abandonar a posição de detentor de conhecimentos e se tornar o mediador de grupos. Os autores defendem a necessidade de se organizar previamente $o$ tempo, os materiais despendidos e o estabelecimento de objetivos claros a serem alcançados pelos alunos de gerações que demandam conteúdos curriculares ofertados por meio de aulas e atividades atrativas, lúdicas e que tragam algo novo em relação às vivências que eles já possuem para que se conquiste sua atenção e participação.

Diante do exposto, a síntese é que as IES necessitam de modernização, a fim de atenderem às próximas gerações e permitam aos seus egressos a inserção no mundo do trabalho através do aprofundamento da compreensão das ciências e do desenvolvimento de competências.

\section{Resultados e Discussão}

Nessa seção, são apresentados os resultados decorrentes da pesquisa de campo, a partir de uma amostragem de 44 respostas, correspondentes 14,9\% do universo de 295 professores. A seguir, no gráfico 1, os dados obtidos referentes à utilização de aulas expositivas:

Gráfico 1 - Respostas referentes ao uso de aulas expositivas.

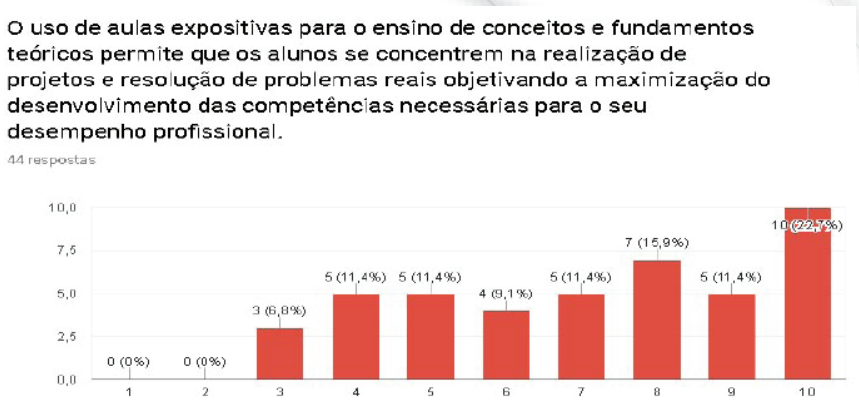

Fonte: elaborado pelos pesquisadores.
A representação estatística referente ao uso de aulas expositivas está detalhada na tabela 1 :

Tabela 1 - Estatística das respostas referentes ao uso de aulas expositivas:

\begin{tabular}{l|c}
\hline MÉDIA & 7,14 \\
\hline DESVIO PADRÃO & 2,33 \\
\hline MODA & 10 \\
\hline VARIÂNCIA & 5,3 \\
\hline
\end{tabular}

Fonte: elaborado pelos pesquisadores.

A média amostral de 7,14 e a moda 10 indicam haver concordância com a assertiva. Dentre os comentários, reforçou-se a importância das aulas expositivas, no entanto foi enfatizado que estas não devem ser a única estratégia utilizada. Requer-se, pois, a utilização de outras metodologias em complementaridade, tais como aulas práticas, estudos de caso, proporcionando alternância de metodologias que busquem captar a atenção do aluno e ampliar sua motivação por meio de metodologias ativas, ou seja: exemplos, experiências próprias do professor, situações reais de problemas, considerando que aulas expositivas sem a interação dos alunos tendem a ser monótonas. A variância em 5,3 demonstra ter ocorrido dispersão das respostas, o que pode ser constatado no gráfico 1. Tal ocorrência, na análise dos pesquisadores, pode sinalizar que o entendimento dos sujeitos à assertiva não significaria necessariamente a adoção de metodologias ativas de aprendizagem por projetos ou resolução de problemas em substituição às aulas expositivas.

Estes comentários confirmam a posição de Zaslavskaya (2018) de que a introdução das metodologias ativas em substituição às aulas expositivas é uma estratégia cada vez mais presente no ensino contemporâneo. Lacerda e Santos (2018) salientam que apenas a utilização do Datashow no ensino universitário adquire contornos de um pseudorrecurso tecnológico que pode encobrir deficiências dos professores nas aulas expositivas.

A seguir, no gráfico 2, apresenta-se os dados obtidos referentes à utilização do E-learning: 
Gráfico 2 - dados obtidos referentes à utilização do E-learning:

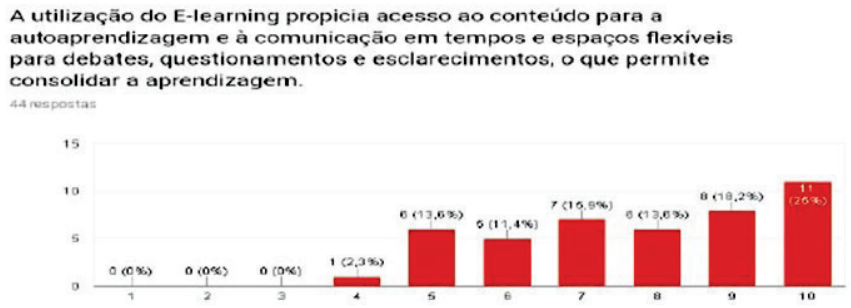

Fonte: elaborado pelos pesquisadores.

A representação estatística referente às respostas à utilização do E-learning está detalhada na tabela 2:

Tabela 2 - Estatística das respostas referentes à utilização do E-learning:

\begin{tabular}{l|c}
\hline MÉDIA & 7,8 \\
\hline DESVIO PADRÃO & 1,85 \\
\hline MODA & 10 \\
\hline VARIÂNCIA & 3,34 \\
\hline
\end{tabular}

Fonte: elaborado pelos pesquisadores.

A média amostral obtida de 7,8 e moda 10 indicam haver concordância com a assertiva. Os comentários dos sujeitos de pesquisa reforçam a possibilidade de utilização das tecnologias digitais, em especial o e-learning, como parte de um processo complementar às aulas presenciais, visando estimular a curiosidade do aluno e, desta forma, possibilitar a aceleração da aprendizagem. Entretanto, a implementação desta prática docente requer disciplina e independência do discente para o aproveitamento da ferramenta, para que cumpra suas responsabilidades distante do contato professor-aluno, além da necessidade de suporte de tutoria para pronto esclarecimento visando minimizar o risco de dispersão e perda de foco. Fini (2018) corrobora tais argumentos, de que nesta sociedade em construção e ebulição tecnológica, o e-learning se destaca como um caminho estratégico para realizar mudanças profundas na educação.

Referente à utilização da aprendizagem híbrida, os dados obtidos estão apresentados no gráfico 3 , a seguir:
Gráfico 3 -Respostas referentes utilização da aprendizagem híbrida:

\begin{abstract}
A aprendizagem híbrida, ao mesclar o ensino presencial com o virtual dentro e fora da escola, oferece aos alunos 0 acesso a um aprendizado mais interessante por combinar atividades presenciais e a distância realizadas através das tecnologias digitais. A centralização da aprendizagem no aluno e não mais na transmissão de conhecimentos pelo professor em sala de aula propicia ao aluno se antecipar, estudando os conteúdos em diferentes ambientes, tornando a sala de aula no local de aprender ativamente através de resolução de problemas, projetos, discussões, laboratórios com o apoio do professor e colaborativamente com os outros colegas e melhor aproveitamento do tempo do professor para intervenções efetivas.
\end{abstract}

44 respostas

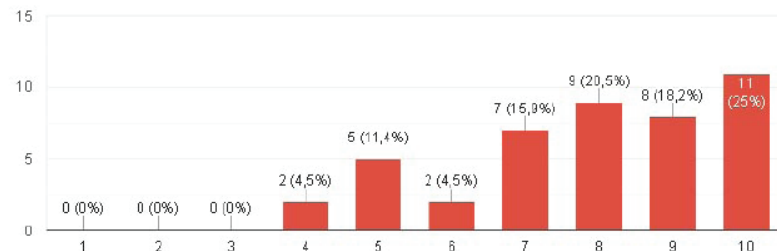

Fonte: elaborado pelos pesquisadores.

A representação estatística referente à utilização da aprendizagem híbrida está detalhada na tabela 3 :

Tabela 3 - Estatística das respostas referentes à utilização da aprendizagem híbrida:

\begin{tabular}{l|c}
\hline MÉDIA & 7,91 \\
\hline DESVIO PADRÃO & 1,83 \\
\hline MODA & 10 \\
\hline VARIÂNCIA & 3,26 \\
\hline
\end{tabular}

Fonte: elaborado pelos pesquisadores.

A média amostral obtida de 7,91 e moda 10 indicam haver concordância com a assertiva. Dentre os comentários obtidos, identificou-se que a opinião dos docentes é que o ensino híbrido é uma tendência e que a mescla do ensino presencial e virtual possibilita envolver o aluno e desenvolver seu interesse na busca de conhecimentos. Complementarmente, o ensino virtual torna-se necessário antes de aulas práticas a fim de que o aluno obtenha melhor aproveitamento da aprendizagem com o conhecimento prévio. Entretanto, para a obtenção de resultados positivos de aprendizagem requer que o docente tenha 
mapeado previamente o repertório de conhecimentos da turma, que as ações em sala de aula sejam convergentes ao projeto pedagógico e, que este esteja alinhado ao perfil profissional que se planeja formar. Este necessita estar contextualizado à sociedade que se deseja construir, na direção de se superar a falta de disciplina, de proatividade e de maturidade que os discentes das novas gerações apresentam frente às exigências.

Os comentários estão em sintonia com a descrição de Cortes, Martins e Medeiros de Souza (2018) para os quais, é importante mudar os modos de aprender e ensinar e que somente o uso de meios digitais não garante a aprendizagem, dado existirem fatores que devem ser considerados, tais como tipo de material, linguagem, estratégias de interatividade síncrona ou assíncrona. Além do mais, a análise necessita de aprofundamento teórico para não considerar apenas a ferramenta, dado que o processo educativo envolve "pessoas". Bruno e Oliveira Silva (2017) concordam com a posição assinalada, pois os estudantes convivem com a tecnologia e os processos de docência necessitam estar sintonizados com as mudanças educacionais ocasionadas pelas tecnologias digitais e em rede. A transformação educacional envolve os alunos, as instituições, os cursos, o professor e a formação docente. Lacerda e Santos (2018) condicionam a aplicação das metodologias ativas baseadas nas TIC à uma formação específica do corpo docente e à autonomia dos discentes, ou seja, que tragam dos níveis anteriores uma aprendizagem significativa que Ihes permita avançar no conteúdo com suporte à distância.

Referente ao uso de softwares e simuladores, os dados obtidos estão apresentados no gráfico 4, a seguir:

Gráfico 4- Respostas referentes ao uso de softwares e simuladores:

O uso de softwares matemáticos, estatisticos, 3D e simuladores aliados à fundamentação teórica contribui para que o aluno desenvolva inovaçōes, tornando-o mais adaptado à realidade do século $X X \mathrm{X}$, em que as condiçöes mudam frequentemente.

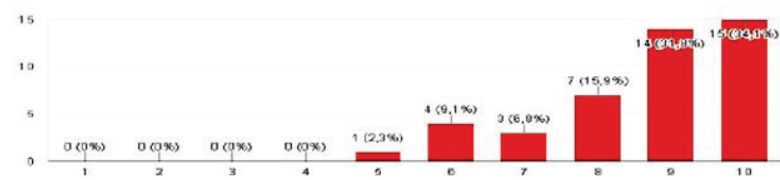

Fonte: elaborado pelos pesquisadores.
A representação estatística referente ao uso de softwares e simuladores está detalhada na tabela 4:

Tabela 4 - Estatística das respostas referentes ao uso de softwares e simuladores:

\begin{tabular}{l|c}
\hline MÉDIA & 8,68 \\
\hline DESVIO PADRÃO & 1,38 \\
\hline MEDIANA & 10 \\
\hline VARIÂNCIA & 1,85 \\
\hline
\end{tabular}

Fonte: elaborado pelos pesquisadores.

A média amostral obtida de 8,68 e moda 10 indicam haver concordância com a assertiva. Dentre os comentários, foi destacada a necessidade de investimentos em Hardwares, Softwares e outras ferramentas que não se limitem a cálculos estruturais e modelagem, mas que incluam geradores de protótipos e mockups, como impressoras 3D. Contudo, torna-se imprescindível o letramento informacional prévio dos discentes a fim de que consigam interpretar os resultados gerados pelos softwares e simuladores. Tais softwares simplificam e automatizam atividades rotineiras como cálculos e desenhos, permitindo dedicar maior tempo na análise crítica das informações e na abstração daí decorrente. Por vezes, tais ferramentas permitem ao discente superar dificuldades de raciocínio espacial ou mecânico, muito embora necessitem possuir a capacidade de realizar os cálculos ou desenhos na ausência de tais ferramentas, sem menosprezar as habilidades interpessoais e de trabalho em equipe. Zaslavskaya (2018) reforça tal argumentação ao alertar que a tecnologia não é a solução de todos os problemas educacionais e que mesmo com este avanço, o ser humano possui emoções e sentimentos. Desta forma, complementa a autora, torna-se necessária uma reflexão acerca das relações com o mundo do trabalho, equilibrando a produtividade com o desenvolvimento humano.

A assertiva referente ao perfil do novo professor, os dados obtidos estão apresentados no gráfico 5, a seguir: 
Gráfico 5 - Distribuição das respostas referentes à demanda do perfil do novo professor:

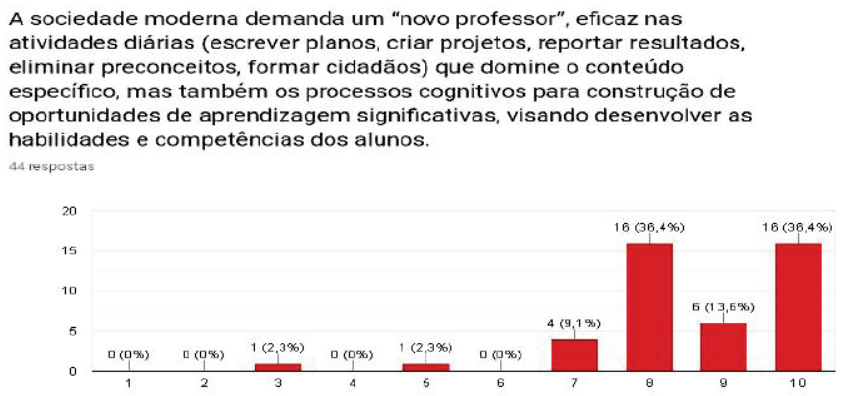

Fonte: elaborado pelos pesquisadores.

O gráfico 5 sinaliza haver elevada concordância quanto à necessidade de um novo comportamento docente que privilegie a aprendizagem, tendo o aluno como ponto de partida para a elaboração do planejamento e prática em sala de aula.

A representação estatística referente às respostas sobre o perfil do novo professor está detaIhada na tabela 5 :

Tabela 5 - Estatística das respostas referentes ao perfil do novo professor:

\begin{tabular}{l|c}
\hline MÉDIA & 8,59 \\
\hline DESVIO PADRÃO & 1,47 \\
\hline MODA & 8 e 10 \\
\hline VARIÂNCIA & 2,11 \\
\hline
\end{tabular}

Fonte: elaborado pelos pesquisadores.

A média amostral obtida de 8,59 e modas 8 e 10 indicam haver concordância com a afirmação acima. Os comentários obtidos relatam que o debate sobre a mudança dos métodos de ensino não é recente e que parte significativa dos docentes do ensino superior não recebeu a preparação didática adequada, submetendo o processo de ensino-aprendizagem a uma experimentação e ao empirismo dos erros e acertos. Identificou-se opinião dos sujeitos quanto à utilização da tecnologia em sala de aula se constituir em uma demanda urgente dos alunos, ao mesmo tempo em que sua utilização está vinculada a investimentos e treinamento de docentes quanto ao desenvolvimento de suas próprias habilidades e competências digitais. O pensamento de Oliveira e Pereira (2018) converge com os comentários obtidos no sentido de que se faz necessário o uso de ferramentas e recursos didáticos digitais que viabilizem práticas significativas para o desenvolvimento de saberes do conhecimento e com base nestes recursos, pode-se verificar que ainda existe uma carência na formação de professores para o uso adequado e pedagógico de recursos didáticos digitais ou não, que auxiliem no ensino e aprendizagem de saberes, em processo de formação inicial ou continuada, evidenciando as lacunas em suas formações, o que por vezes dificulta trabalhar determinados conteúdos e o uso de certas práticas, que seriam viáveis através do uso pedagógico desses recursos.

Os professores concebem que possuem o papel de formar cidadãos para solucionar problemas do dia a dia em suas atividades profissionais. A esse respeito, Zaslavskaya (2018) entende que atualmente o docente se depara com a tarefa de não apenas instruir, mas educar pessoas que possuam princípios morais, empreendedor, competente, autônomo, capaz de decidir acerca da implementação de tarefas profissionais, prevendo as consequências das suas soluções adotadas em cooperação com outros profissionais.

$\mathrm{Na}$ pesquisa de campo, os sujeitos de pesquisa registraram comentários julgados como relevantes a respeito do tema "Práticas docentes visando o desenvolvimento das competências dos profissionais para a economia digital". Foi destacada a necessidade da reflexão do professor visando a ressignificação da educação, pois todas as profissões deverão passar por transformações (PAMBOUKIAN; KANAANE, 2018b); (FAVA 2018) o docente necessita de capacitação e treinamentos $\mathrm{e}$ atualizações em função do avanço das tecnologias e demandas sociais (FINI, 2018).

Destacou-se também, a necessidade da infraestrutura tecnológica objetivando a obtenção de bons resultados do trabalho docente visando aprimorar a aprendizagem, rever as práticas de acordo com a realidade da instituição, do ambiente, das tecnologias disponíveis e dos próprios alunos. As tecnologias digitais são ferramentas que possibilitam elevar a capacidade humana no ensino-aprendizagem. As transformações estão ocorrendo nas empresas dos setores produtivos, públicos e em toda a sociedade. $O$ desenvolvimento das habilidades e das competências profissionais dependem de metodologias, tecnologias, processos, professores e gestores capacitados para lidar no mister da educação, 
assim como de políticas e diretrizes. Isso se coaduna com a posição de Pereira e Silva et al (2017) que consideram a necessidade de professores dispostos à uma mudança de paradigma, que reconheçam a relevância das competências para si próprios como profissionais, de forma a facilitar o desenvolvimento das competências por parte dos alunos, sendo a gênese e fio condutor da compreensão do conjunto de competências elencadas na literatura internacional e reconhecida como relevantes do ponto de vista educativo quer na formação dos alunos, enquanto competências para a vida, quer na capacitação dos professores, enquanto competências profissionaís.

Ainda que sejam identificadas carências no letramento digital de muitos estudantes, considerando lacunas na capacidade analítica e de discernimento crítico perante a cultura digital, o fato é que eles já estão inseridos nesses ambientes de informação da cibercultura. Cabe, portanto, ao docente, imigrante digital não somente o uso utilitário da tecnologia, mas um trabalho intenso de letramento digital que suporte a produção de conhecimento (BRUNO; OLIVEIRA SILVA, 2017).

\section{Considerações finais}

Concebe-se que a questão de pesquisa, ou seja, quais as práticas docentes que contribuem para o desenvolvimento das competências profissionais necessárias à economia digital foram respondidas, os objetivos propostos foram atingidos, ampliando-se a compreensão sobre o tema.

Constatou-se que o modelo tradicional de ensino enciclopedista, fragmentado por meio de disciplinas, baseado na transmissão de conhecimentos pelo docente e passividade do aluno, fundado na memorização e reprodução e avaliação da capacidade de memorização do aluno nos diversos níveis de educação tem sido questionado, estando relacionado aos elevados índices de evasão e repetência, bem como provocando distorções profissionais no ensino superior (LACERDA; SANTOS, 2018).

Entende-se que a educação tradicional no Brasil tem apresentado rendimento insuficiente para suprir às necessidades do país. Recentemente, tem-se revisitado o modelo de escolas que implementam uma cultura acadêmica de excelência, elevados padrões éticos, meritocracia e extrema disciplina por apresentarem resul- tados de aprendizagem superiores à média das escolas públicas. De fato, tais escolas apresentam resultados sob essas condicionantes, mas o modelo dificilmente seria replicável à maioria das escolas, portanto, não se constituindo numa solução viável. De fato, a escola tradicional, com ensino centrado no professor, alunos passivos, relacionamento professor-aluno impessoal e sem a participação dos pais tem sido a fórmula para o insucesso. Se de um lado, a adoção de metodologias ativas de ensino num contexto educacional ultrapassado não alcançará plenamente os resultados esperados, por outro, uma nova concepção não será adequadamente implantada com métodos tradicionais. Desta forma, ao propor uma abordagem educacional contemporânea, surge também a necessidade de se alterar o modelo de avaliação, combinando a função diagnóstica, formativa e somativa em consonância com a tecnologia digital a ser utilizada, objetivando influenciar a cultura vigente por meio de práticas acadêmicas híbridas oriundas da cibercultura e que atendam às demandas existentes, integrando práticas culturais com a universidade, num processo permanente de construção e disseminação do conhecimento (SILVA; BEZERRA, 2018).

Observa-se que a educação superior no Brasil não acompanhou as mudanças vertiginosas no cenário sociotécnico mundial das últimas décadas que interfiram e transformaram as formas de relacionamento humano e também o acesso, produção e socialização de conhecimentos. Apesar das TIC fazerem parte do cotidiano educacional e acadêmico, elas não têm sido incorporadas nos processos formativos, apesar de docentes e discentes utilizarem em suas produções e ações formativas e científicas. Pesquisas revelam que a formação docente apresenta ações dispersas visando à incorporação de tais recursos em suas práticas de ensino-aprendizagem para a mudança de uma cultura que hoje é notadamente digital (BRUNO; OLIVEIRA SILVA, 2017).

Evidenciou-se que o conjunto de descobertas científicas e tecnológicas vinculados à quarta revolução industrial vem transformando o trabalho, alterando as profissões, modificando o modo de vida das pessoas, trazendo impactos também para os CST.O século XXI apresenta indícios da consolidação da sociedade globalizada num estágio pós-industrial devido à combinação de fatores como a desindustrialização e a redução na quantidade de postos de trabalho oferecidos pelo setor industrial, ocasionada pela elevação da produtividade 
devido à adoção das tecnologias digitais nos processos produtivos (PAMBOUKIAN, 2018). Decorre do exposto, a existência de um anacronismo ao se manter uma escola do século XX, com professores formados por métodos do século XIX, para alunos do século XXI.

Depreende-se que as formas de desenvolver as competências estão relacionadas a formação dos professores, à adoção das tecnologias em associação às metodologias ativas de ensino, utilização da sala de aula invertida e da consciência dos alunos sobre a necessidade de seu protagonismo no aprendizado (PAMBOUKIAN, 2018).

Embora os professores necessitem de capacitação para desenvolvimento das competências, ficou evidenciada a necessidade de se adotar novos paradigmas, em um modelo educacional como alternativa à transmissão de conteúdos em massa. Assim, a utilização do modelo de competências, bem como o ensino dual (combina a sala de aula com a atividade laboral) e híbrido (presencial e à distância) surgem como alternativas para se avançar nesta direção. Paradoxalmente, o professor é ao mesmo tempo o ponto principal para a educação de qualidade e pode ser o obstáculo à sua modernização (PAMBOUKIAN, 2018a).

Ainda que pareça consensual que a sociedade em sua fase digital se organiza cada vez mais a partir das mídias e que elas cumprem a função de mediadoras entre os atores sociais e a cultura, (re) configurando as possibilidades de interações coletivas, não é descartável a necessidade urgente de a educação enfatizar a importância das transformações socioculturais promovidas pelas tecnologias (CORTES; MARTINS; MEDEIROS DE SOUZA, 2018).

Fini (2018) vê que numa sociedade digital em construção, a ebulição tecnológica de suas transformações tem exigido constantes adaptações e mudanças profundas na educação como um todo. Um país com as dimen- sões do Brasil só pode conseguir superar sua defasagem educacional por meio do uso intensivo de tecnologias em rede, da flexibilização dos tempos e espaços de aprendizagem, da gestão integrada de modelos presenciais e digitais para favorecer oportunidades para que $\mathrm{o}$ aluno aprenda a aprender nos bancos escolares e depois deles. Para um futuro próximo, em razão dos desafios postos perante o avanço tecnológico e as mudanças da sociedade e da economia global, torna-se imperioso que as IES e o país busquem ajustes em reformas que vislumbrem questões significativas para que possamos competir no mercado internacional e, desse modo, consolidarmo-nos como referência acadêmica no Ensino Superior.

Embora o presente estudo tenha contemplado em sua pesquisa de campo as práticas docentes aplicáveis ao nível superior apropriadas ao atendimento das demandas do século XXI listadas por Zaslavskaya (2018), efetuou-se um recorte de modo que parcela significativa das práticas docentes tais como: aprendizagem invertida; adição de jogos; aprendizagem móvel, remota e flexível; armazenamento em nuvem; informações de mídia; redes sociais; atualização constante de conteúdos; educação personalizada; educação coletiva; aprendizagem integrada e uso de softwares de gestão da sala de aula poderão ser objetos de publicações posteriores.

À guisa de conclusão, tem-se que as mudanças paradigmáticas vigentes na sociedade brasileira nos remetem à possibilidade específica acerca da ressignificação dos valores que embasam as IES tanto na sua estrutura quanto no direcionamento estratégico e ações voltadas ao processo ensino-aprendizagem e aos cursos de tecnologia. Diretrizes possibilitarão 0 equacionamento de políticas e práticas que atuarão como âncoras à atuação docente frente ao desenvolvimento de competências no âmbito da economia digital. Estudos posteriores serão benvindos, visando ampliar o escopo de debate e compreensão da temática proposta. 


\section{REFERÊNCIAS}

ARAÚJO, Ulisses F. A quarta revolução educacional: a mudança de tempos, espaços e relações na escola a partir do uso de tecnologias e da inclusão social. In: ETD - Educação Temática Digital 12 (2011), esp., pp. 31-48.

ARBIX, G. et al. O Brasil e a nova onda de manufatura avançada. Novos estudos. CEBRAP São Paulo, v. 36, n. 03, p. 29-49, nov. 2017.

BARSUKOV, D. et al. Professional education for digital economy: trends and prospects. MATEC Web of Conferences v. 170, n. 01063,2018 . Disponível em: <https:// doi.org/10.1051/matecconf/201817001063SPbWOS CE-2017>.

BONVILLIAN, William; SANJAY, S. The Quest for Quality Jobs. Issues in Science and Technology, Fall. v.35, n. 1 , p. $28-30$.

BRUNO, Adriana Rocha; OLIVEIRA SILVA, Judilma Aline. Percursos e experiências no ensino superior: múltiplas aprendizagens para docências na cultura digital. Laplage em Revista (Sorocaba). v. 3, n. 2, maio-ago. 2017, p. 24-33.

CASTRO, Eder Alonso. et al. Ensino Híbrido: Desafio da contemporaneidade? Periódico Científico Projeção e Docência. v.6, n.2, 2015.

CONFEDERAÇÃO NACIONAL DA INDÚSTRIA. Desafios para a indústria 4.0 no Brasil. - Brasília: CNI, 2016.

CORTES, T. P. B. B.; MARTINS, A. O.; MEDEIROS DE SOUZA, C. H. Educação midiática, educomunicação e formação docente: parâmetros dos últimos 20 anos de pesquisas nas bases Scielo e Scopus. Educação em Revista. Belo Horizonte. v.34, 2018.

DANTAS, L. J.; PAMBOUKIAN, S.; KANAANE, R. Perspectivas de formação e do mercado de trabalho para o Tecnólogo em Soldagem. Anais do $9^{\circ}$ Congresso Brasileiro de Engenharia de Fabricação. Joinville, Santa Catarina, Brasil, 2017. p. 95.
FADEL, Charles; BIALIK, Maya; TRILLING, Bernie. Educação em quatro dimensões. Center for Curriculum Redesign, Boston, MA, 2015.

FAVA, Rui. Trabalho, educação e inteligência artificial: a era do indivíduo versátil. Porto Alegre: Penso, 2018.

FINI, M. I. Metodologias inovadoras de aprendizagem e suas relações com o mundo do trabalho: desafios para a transformação de uma cultura. Administração: ensino e pesquisa. Rio de Janeiro, v. 19, n. 1, p. 176-183, jan.-abr. 2018.

LACERDA, Flávia Cristina Barbosa; SANTOS, Letícia Machado dos. Integralidade na formação do ensino superior: metodologias ativas de aprendizagem. Avaliação, Campinas; Sorocaba, SP, v. 23, n. 3, p. 611-627, nov. 2018.

MASETTO, Marcos Tarciso; NONATO, Bréscia; MEDEIROS, Zulmira. Inovação curricular no Ensino Superior: entrevista com Marcos Tarciso Maseto. Rev. Docência Ens. Sup., Belo Horizonte, v. 7, n. 1, p. 203-210, jan./ jun. 2017.

MORÁN, J. M. Mudando a educação com metodologias ativas. Coleção Mídias Contemporâneas. In: DE SOUZA, Carlos Alberto; MORALES, Ofelia Elisa Torres. (orgs.). Convergências Midiáticas, Educação e Cidadania: aproximações jovens. Foca Foto-PROEX/UEPG, v. II, 2015.

OLIVEIRA, Gisele Pereira; PEREIRA, Ana Carolina Costa. O uso da engenharia didática como ferramenta facilitadora para utilização e produção de objetos de aprendizagem a partir da formação inicial e continuada de professores de matemática. Boletim Cearense de Educação e História da Matemática - v. 05, n. 13, 48-65, 2018. DOI: 10.30938/bocehm.v5i13.19. 
PAMBOUKIAN, S. As competências requeridas no século XXI dos egressos dos cursos superiores de tecnologia Mecânica e Soldagem da Fatec-SP. São Paulo: CEETEPS, 2018. 196 f. Dissertação (Mestrado Profissional em Gestão e Desenvolvimento da Educação Profissional e Tecnológica) - Centro Estadual de Educação Tecnológica Paula Souza, 2018.

PAMBOUKIAN, Sergio; KANAANE; Roberto. Expectativas dos alunos do curso de tecnologia em soldagem da Fatec-SP frente ao mercado de trabalho. In: Workshop de Pós-graduação e Pesquisa do Centro Paula Souza, XI. Anais... São Paulo: Ceeteps, 2016. p.458-467.

O Ensino Tecnológico e os processos produtivos no Brasil. In: Workshop de Pós-graduação e Pesquisa do Centro Paula Souza, XII. Anais... São Paulo: Ceeteps, 2017. p.849-858.

O tecnólogo e as competências para o século XXI. In: Simpósio de Ensino Técnico e Tecnológico do Centro Paula Souza. Anais... São Paulo: Vo SEMTEC, 2018a. p. 60-66.

CST em Mecânica e Soldagem da Fatec-SP: ampliação das competências dos egressos na era da transformação digital. In: Workshop de Pós-graduação e Pesquisa do Centro Paula Souza, XIII. Anais... São Paulo: Ceeteps, 2018b. p.31-40.

PEREIRA E SILVA, I. et al. As competências para o século XXI na perspectiva dos professores: Um estudo na região centro-oeste de Portugal. Revista Iberoamericana de Educación, v. 74, p. 193-216 - OEI/CAEU, 2017.

RICHTER, Alexander; HEINRICH, Peter; STOCKER, Alexander; SCHWABE, Gerhard. Digital Work Design. Business \& Information Systems Engineering, v. 60, n. 3, p. 259-264, 2018.

RODRIGUES, Tereza Cristina; TELES, Lucio França. O uso de mensagens eletrônicas instantâneas como recurso didático. Rev. bras. Estud. pedagog., Brasília, v. 100, n. 254, p. 17-38, jan./abr. 2019.
SAMPIERI R. H.; COLLADO C. F.; LUCIO M. P. B. Metodologia de Pesquisa. 5. ed. Porto Alegre: Editora Penso, 2013.

SCHWAB, Klaus. A quarta revolução industrial. 1. ed. São Paulo: Edipro, 2016.

SCHWARTZ, Marc S. et al Neuroscience knowledge enriches pedagogical choices. Teaching and Teacher Education. v. 83, Jul. 2019, p. 87-98.

SILVA L. T. G.; BEZERRA, I. S. Hibridações da cultura acadêmica com a cibercultura: análise das práticas acadêmicas no ambiente virtual de aprendizagem Moodle. Educação em Revista. Belo Horizonte. v. 34, 2018.

TAPSCOTT, Don. The digital economy: promise and peril in the age of networked intelligence Mcgraw-hill, 1995.

TOBÓN, S. Formación Integral y Competencias. Bogotá, Colombia: Eco Ediciones, 2013.

UNESCO. A qualidade social da educação brasileira nos referenciais de compromisso do Plano e do Sistema Nacional de Educação. São Paulo, CNE, dez. 2015. Disponível em: $<$ http://portal.mec.gov.br/index.php?option=com docman\&view=download\&alias $=41841$-estudo-sobre-cenario-internacional-das-areas-educacional-empresarial-pdf\&category slug=maio-2016-pdf\&ltemid=30192> Acesso em: 15 jun. 2017.

ZASLAVSKAYA, O. Yu. The impact of global processes of informatization the development of the modern education system in a digital economy. RUDN Journal of Informatization of Education, v. 15, n. 3, p. 271-281, 2018. DOI 10.22363/2312-8631-2018-15-3-271-281. 